\title{
Development and analysis of dynamical mathematical models of greenhouse climate: A review
}

\author{
I.L. López-Cruz ${ }^{1}$, E. Fitz-Rodríguez ${ }^{1}$, R. Salazar-Moreno ${ }^{1}$, A. Rojano-Aguilar ${ }^{1}$ and M. Kacira ${ }^{2}$ \\ ${ }^{1}$ Graduate Agricultural Engineering Program, University of Chapingo, Chapingo, Mexico \\ ${ }^{2}$ Agricultural and Biosystems Engineering Dept., University of Arizona, Tucson, USA
}

\section{Summary}

This paper summarizes the main developments achieved up to now on dynamical models of the greenhouse climate, regarding their structure, analysis, parameter estimation and model performance. The systems state-space approach is followed in order to describe main models' structure features. The physical processes included in the dynamic equations of greenhouse climate are emphasized. The type of equations used, either differential equations, difference equations or transfer functions are described. The dynamic models of greenhouse climate are classified in mechanistic and black-box models. Mechanistic models are mainly focused on the knowledge of the greenhouse system whereas black-box models are more used for applications, including: control, optimization and design of the greenhouse system. Main results of this study are that models of greenhouse climate used mostly ordinary differential equations either to know more the system or to control and optimize it. Only few models used difference equations or ARX. Also more complex greenhouse climate models have been developed to get insight of the greenhouse system while models with few states are more useful for control and optimization purposes. The dynamic models of greenhouse climate have mostly founded on the first law of thermodynamics, namely (energy/ enthalpy) analysis and conservation of mass. Furthermore, although almost all the models have been calibrated and evaluated using measured data from the system, there is a lack of uncertainty and sensitivity analysis in the development of greenhouse climate models. In fact, none of the revised models were subjected to an uncertainty analysis. Some models of greenhouse environment have been reported with only a preliminary sensitivity analysis; a few of them with a formal local sensitivity analysis and none with a global sensitivity analysis.

\section{Keywords}

differential equations, difference equations, model calibration, model evaluation, sensitivity analysis, transfer function, uncertainty analysis

\section{Introduction}

The greenhouse environment is a complex dynamical system characterized roughly by two main subsystems: the microclimate and the crop. This review is focused on the physics of the greenhouse microclimate and its mathemat-

\section{Significance of this study}

What is already known on this subject?

- Dynamic models of greenhouse climate have been developed taking into account only the first law of thermodynamics.

What are the new findings?

- Exergy, uncertainty and sensitivity analyses have not extensively been used in the development of greenhouse climate models.

What is the expected impact on horticulture?

- To contribute improving the mathematical modeling of greenhouse environment.

ical modeling. In general, the greenhouse microclimate has been modeled mathematically in order to both increase the knowledge of the system and also to use the microclimate representation for improved optimization, climate control or design of the greenhouse to achieved desired environment (Bot, 1989a; Boaventura-Cunha, 2003). In either case, a general modeling procedure should follow several stages before model's application; qualitative and quantitative model structure postulation, uncertainty analysis, sensitivity analysis, parameter estimation (or model calibration), and model evaluation (Rabbinge and De Wit, 1989; Haefner, 2005; Van Straten, 2008; Wallach et al., 2014). Dynamic models are built to augment our knowledge of systems in general and to enhance the understanding on the dynamics of the greenhouse environment. Dynamic models could be represented by continuous-time or discrete-time equations. The first approach is given by a set of ordinary first-order differential equations which are usually nonlinear. The second type is given by a set of first order difference equations. In general, there are four types of dynamical models for systems control and optimization, including the greenhouse system: state-space continuous-time dynamical models, state-space discrete-time dynamical models, continuous-time transfer functions, and discrete-time transfer functions. Model calibration concerns the determination of values for more uncertain model parameters using measured data of model outputs so that predictions are comparable to observed data (Wallach et al., 2014). Uncertainty analysis is understood as the quantification of uncertainty in model outputs whereas sensitivity analysis is the study of how uncertainty in the mathematical model output can be assigned to different sources in the model inputs (Saltelli et al., 2000, 2004, 2008). Model evaluation is the determination of the value of a model with respect to its proposed use (Wallach et al., 2014). 


\section{Dynamic models to increase the knowledge of the greenhouse system (mechanistic models)}

One of the first mechanistic dynamic models of greenhouse climate was developed by Bot (1983). The state variables include four temperatures: greenhouse cover, air, crop canopy and four layers of soil as well as air and soil humidity. The physical processes included in the unsteady-state energy balance were convection, conduction, ventilation and radiation. Whereas, the mass balance took into account the processes of convection, ventilation, transpiration and condensation. The input variables were air temperature, humidity, solar radiation and wind velocity outside the greenhouse. In a more complex and detailed model, carbon dioxide concentration of the air was considered as another state variable (Bot, 1989b) in each greenhouse compartment. Thus, the physical and biological processes in the detailed model, were $\mathrm{CO}_{2}$ injection, crop photosynthesis and crop respiration rates. In the latter model, the temperature of heating pipes was also in the energy balances. The first model was of nine state-variables and the second had ten state-variables. Models' predictions were compared against measurements. These models were developed for glasshouses.

Takakura (1993) proposed a pioneering physical model of greenhouse climate applied to polyethylene greenhouses with two layers. The state variables were temperature of the two plastic layers, temperature of the air, humidity ratio, temperature of the crop, and up to five soil layers temperatures. However, a greenhouse climate model with a fan-pad system was extended up to twelve states (Takakura and Fang, 2002). The physical process included were radiation (short and long wave length), convection, conduction, condensation and transpiration (Takakura et al., 1971). The behavior of these models has been investigated by calibration and evaluation.

A fairly detailed mechanistic dynamic model (KASPRO) of the greenhouse climate was devised by De Zwart (De Zwart, 1996, 1997). The state variables included air temperature, carbon dioxide concentration and humidity (water vapor or partial vapor pressure). In the case of the temperature, unsteady-state balances were carried out at the greenhouse cover, the air above a thermal screen, air below a thermal screen, on the crop canopy, in the floor and in six soil layers. For carbon dioxide and air humidity, mass balances were performed above and below a thermal screen. Thus, the KASPRO model has a total of sixteen state variables. The input variables were temperature of the sky, temperature outside the greenhouse, temperature of a deep soil layer, temperature of upper and lower heating pipe, external vapor pressure, carbon dioxide concentration and wind speed outside the greenhouse. Control variables were $\mathrm{CO}_{2}$ supply, window aperture, thermal screens and artificial lighting. The physical processes involved in the mass and heat unsteady-state balances included radiative heat exchange, convective exchange, ventilation, condensation, transpiration and conduction. This model was developed for glasshouses. Although the quality of the model predictions were compared against measurements from Dutch glasshouses (De Zwart, 1996) only recently other researchers have used the KASPRO model and they have performed its calibration and evaluation (Luo et al., 2005).

A dynamic detailed physical model of greenhouse climate named Gembloux Dynamic Greenhouse Climate Model (GDGCM) was proposed by Pieters et al. (1996a, b) with state variables temperature and humidity. Temperature dynamics was modelled at the greenhouse cover, the air inside the greenhouse, crop canopy and four soil layers. The water vapor concentration of the air was another state variable. The dynamic model consisted of a total of eight state variables. The input variables were subsoil and sky temperatures; air temperature, solar radiation, relative humidity and wind speed, all measured outside the greenhouse. Another version of the GDGCM (Pieters and Deltour, 1997) incorporated other states variables considering five soil layers, the energy balance at a second cover and the air temperature inside the two covers. The physical processes included in this model were convection, radiation, conduction, condensation, and crop transpiration. The GDGCM model was calibrated and evaluated with data from Dutch glasshouses. This model has been calibrated and evaluated with measurements collected in a greenhouse with polyethylene cover and naturally ventilated (Mashonjowa et al., 2013a, b).

A dynamic model of greenhouse climate was developed for unheated Mediterranean greenhouses (Navas et al., 1998; Baptista et al., 2010). The state variables were temperature of the substrate, soil, crop, air, and greenhouse cover, besides the air humidity. Input variables included air temperature, humidity, wind speed and solar radiation outside of the greenhouse. A preliminary (neither local nor global) sensitivity analysis was carried out. The performance of the model was evaluated against measurements (Baptista et al., 2000, 2001). Another model for Mediterranean greenhouses has been proposed (Tavares et al., 2001). The state variables in this model involved only the cover temperature, the air temperature and soil temperature at several soil layers. The physical processes considered in the energy balance were radiation, convection, condensation, ventilation, evaporation from soil to the air. The effect of the crop was neglected. The input variables were solar radiation, air temperature and wind velocity outside the greenhouse. These models were developed for greenhouses with a polyethylene cover.

A closed greenhouse can be conceptualized as a greenhouse system with no windows. The main properties are the presence of seasonal thermal energy storage, the use of a heat pump for the heating process and the existence of a heat exchanger for the cooling process (Vadiee and Martin, 2012). A dynamic model of air temperature and humidity was developed and analyzed in a closed greenhouse using the TRNSYS software (Vadiee and Martin, 2013a, b). The model has temperature and moisture as state variables. The physical processes considered in the unsteady-state energy and mass balances were gain of shortwave radiation, loss of longwave radiation, conduction, convection, crop transpiration and the heat transfer between the greenhouse and the thermal energy storage. The input variables were solar radiation and control variables as air intake and heating system. The model was used to evaluate demands of heating and cooling (Vadiee and Martin, 2014) in glasshouses.

The Watergy project proposed a closed-greenhouse with a solar chimney inside the greenhouse in which a cooling duct contained an air-to-water heat exchanger connected to a heat accumulator (Zaragoza et al., 2007). A physical dynamic model was developed for the Watergy greenhouse (Speetjens et al., 2009, 2010). The physical processes considered in their model included radiation, convection, conduction, condensation, and crop transpiration. The model took into account four compartments of the greenhouse such as crop, inner roof, heat exchanger, and soil. The state variables consisted of canopy temperature and moisture in 
the crop compartment, air temperature and moisture in the inner roof compartment, the temperature and moisture of $n$ sub-compartments of the heat exchanger, the temperature of the water of $n$ sub-compartments of the heat exchanger, the temperature of solids (soil and greenhouse construction) in the crop compartment, the temperature of solids in the inner roof compartment and the temperature of the heat storage of $m$ (up to 12) sub-compartments (Speetjens et al., 2006, 2010). The input variables of the model are solar radiation, air temperature, air humidity outside the greenhouse. The model was calibrated using a Controlled Random Search algorithm and also evaluated using data collected in Almeria, Spain. Only a preliminary sensitivity analysis of the model parameters was done (Speetjens, 2008).

Several concepts of solar greenhouses have been proposed, recently. The main characteristic of a solar greenhouse is a system that proposes no usage of fossil fuels (Bot et al., 2005). In one concept a solar greenhouse has a cover with higher transmissivity and higher heat insulation than a conventional greenhouse. An aquifer is used for energy storage. During summer, the greenhouse can be cooled by cold water using a heat exchanger. For winter time the greenhouse can be heated with warm water by using a heat pump. A heat pump, heat-exchanger, ventilation with heat recovery and the use of cooling nets are characteristic control elements of a solar greenhouse (Van Ooteghem et al., 2005). A dynamic model of the solar greenhouse was proposed by Van Ooteghem (2007). The state variables of the model were air temperature above and below the screen, canopy temperature, cover temperature, soil temperature, lower and upper heating net temperature, thermal screen temperature, carbon dioxide concentration above and below screen, air humidity above and below screen, aquifer energy content and crop biomass. Outdoor shortwave solar radiation, outdoor wind speed, outside air temperature, wet bulb temperature, sky temperature and outdoor $\mathrm{CO}_{2}$ concentration were the input variables (disturbances) while valve position of $\mathrm{CO}_{2}$ supply, window opening, thermal screen closure, ventilation heat recovery, net valve position (lower/upper), heat exchanger valve positon and heat pump valve position formed the control input variables. Because the dynamic model was built based on the models proposed by Bot (1983) and De Zwart (1996), the physical processes were the same as they were incorporated in those models. A local sensitivity analysis of the model parameters was carried out by deriving and solving the dynamic sensitivity equations. The model was calibrated and evaluated (Van Ooteghem, 2007) using measurements from Dutch glasshouses.

A mathematical model for another solar greenhouse system which is focused on carbon dioxide capture has been proposed recently (Effat et al., 2015). The states of the model were carbon dioxide concentration in the greenhouse, humidity ratio, air temperature, cover temperature, canopy temperature and soil temperature of several soil layers. The input variables were the solar radiation, air temperature, humidity and wind speed outside of the system. Furthermore, the control inputs included carbon dioxide injection rate, dehumidification and evaporative cooling. The main physical and biological processes included in the energy and mass balances were convection, conduction, condensation, radiation, ventilation, crop transpiration and crop carbon dioxide assimilation. The model was evaluated with data collected in a polyethylene greenhouse located in Almería, Spain.

A semi-solar greenhouse system is oriented in order to capture larger amounts of solar radiation than conventional structures, uses a thermal screen and has a concrete north wall to storage energy (Taki et al., 2016, 2018). A dynamic model with six states was proposed and evaluated recently (Taki et al., 2016). The states of the model were the temperature of air below screen and above screen, crop, cover, thermal screen and soil. The unsteady-state energy balance included short and long wave radiation, convention, conduction and crop transpiration. The model has as inputs global solar radiation, air temperature and relative humidity. The model has been tested against measurements from a glasshouse (Mohammadi et al., 2018). Another innovative greenhouse system with solar collectors on the roof was built and studied by using a dynamical thermal model which included the temperature of cover, air, soil surface and two soil layers (Joudi and Farhan, 2015). The physical processes considered were radiation, convection and conduction. The model was evaluated with data from the glasshouse proto-type.

TABLE 1. Mechanistic dynamic models of greenhouse climate.

\begin{tabular}{|c|c|c|c|c|c|c|c|c|}
\hline Model/author & States & Inputs & Type & Calibration & Evaluation & UA & SA & Greenhouse type \\
\hline Takakura & $8 / 10 / 12$ & To, RHo, Ro, Wo & ODEs & Yes & Yes & No & No & Polyethylene GH \\
\hline Bot & $9 / 10$ & To, RHo, Ro, Wo & ODEs & Yes & Yes & No & No & Glasshouses \\
\hline KASPRO & 16 & Tsky, To, Tsd, Tpu, Tpl, VPo, $\mathrm{CO}_{2} \mathrm{O}$, Wo & ODEs & Yes & Yes & No & No & Glasshouses \\
\hline GDGCM & $8 / 11$ & Tsky, To, Ro, RHo, Wo, Tsd & ODEs & Yes & Yes & No & No & Glasshouses \\
\hline Baptista & $4 / 6$ & To, RHo, Ro, Wo & ODEs & Yes & Yes & No & Preliminary & Polyethylene GH \\
\hline Solar-1 & 15 & Ro, Wo, To, Tbo, Tsky, $\mathrm{CO}_{2} \mathrm{O}$, & ODEs & Yes & Yes & No & Local SA & Glasshouses \\
\hline Solar-2 & 8 & Ro, To,RHo,Wo & ODEs & Yes & Yes & No & No & Polyethylene GH \\
\hline CSG & 7 & To, Ro, Wo, & ODEs & Yes & Yes & No & No & Polyethylene GH \\
\hline Watergy & 10 & Ro, To, Rho, Wo & ODEs & Yes & Yes & No & Preliminary & Polyethylene GH \\
\hline Closed-GH & 4 & Ro, Airin, Heating & ODEs & Yes & Yes & No & No & Glasshouses \\
\hline Taki & 6 & Ro, RHo, To & ODEs & Yes & Yes & No & No & Glasshouses \\
\hline Joudi & 5 & Ro, To, Tsd & ODEs & No & Yes & No & No & Glasshouses \\
\hline Reyes-Rosas & 6 & Ro, To, RHo, Tsd, Wo & ODEs & Yes & Yes & No & No & Polyethylene GH \\
\hline
\end{tabular}

To: outside air temperature, Tsky: sky temperature, $\mathrm{RHo}$ : outside relative temperature, Ro: global solar radiation, Wo, wind velocity, Tpu: air temperature above thermal screen, Tpl: air temperature below thermal screen, VPo: outside vapor pressure, $\mathrm{CO}_{2} \mathrm{O}$ : carbon dioxide outside the greenhouse, Tsd: depth soil layer temperature, Tbo: outside wet bulb temperature, Airin: air intake, ODEs: ordinary differential equations, UA: Uncertainty analysis, SA: Sensitivity analysis. 
Another example of solar greenhouses is the Chinese solar greenhouse (CSG) used mainly in Northern China. This system has a north heat storage wall, a partial north cover and a south cover. During the night a blanket made of insulating material is laid over the south roof (Yang, 2012; Wei et al., 2016). A simplified dynamic model of the climate of a CSG was developed recently (Du et al., 2012). The whole greenhouse was divided in several volumes and the change in time of air and soil temperature was modeled dynamically. The unsteady-state energy balance of the greenhouse air considered the incoming solar radiation, the convection across the cover, the heat transfer between soil and air, the heat transfer between plants and the air, the loss of energy due to ventilation and the heat supply by a heating system. The soil temperature was modeled by the conduction equation. Model predictions were compared against a typical Chinese solar greenhouse.

Recently, a dynamic model was developed for the environment of polyethylene greenhouses with polypropylene soil mulch (Reyes-Rosas et al., 2017). The state variables of the model were temperature of the greenhouse cover, air, polypropylene mulching and the soil layers. The input variables were the outside solar radiation, wind speed, and air temperature. The physical processes taken into account were conduction, convection, radiation, natural ventilation and crop transpiration. The model was calibrated and evaluated with data collected in plastic greenhouses from Almería, Spain.

Table 1 summarizes the most relevant characteristic of mechanistic dynamic models of greenhouse environment.

\section{Dynamic models to optimize and control the greenhouse system (mechanistic and black-box models)}

Mathematical models used to control the greenhouse climate depend on the control approach. Recent reviews on control approaches applied in greenhouse cultivation revealed that the main control methods mostly applied to the greenhouse environment included classical proportional-integral-derivative (PID), optimal, model predictive, adaptive, feedback and feedforward control and intelligent control with fuzzy systems and neural networks (Van Straten et al., 2011; Lopez-Cruz et al., 2014). Table 2 shows the most relevant characteristics of dynamic model of the greenhouse climate that have been used in optimal and predictive control.

\section{Greenhouse climate models for proportional-integral- derivative (PID) control}

Some of the first models of the greenhouse climate for control purposes were proposed by Udink ten Cate (1983). The dynamics of air temperature was modeled by first-order transfer functions with time-delay (Udink ten Cate and Van de Vooren, 1984; Udink ten Cate, 1985). The parameters of these greenhouse climate feedback/feedforward control models were determined from data following a system identification procedure or black-box modelling approach. The transfer function of a system is the representation in the Laplace domain of the ratio between the output and the input variable. Transfer function can also be obtained by linearizing around an operating point a nonlinear dynamical model of greenhouse climate. However, using these models, the design of single-input single-output (SISO) control system is only possible. An advantage of these models is that they allow the use of several classical methods such as root-locus, PID, frequency response, state-space and digital control in designing a control system. For instance a model of the greenhouse air temperature given by a transfer function of first-order system with time-delay has been used to design a pseudo-derivative algorithm for controlling temperature in a greenhouse (Setiawan et al., 2000).

\section{Greenhouse climate models for optimal control}

The first model of the greenhouse climate with optimal control purposes was proposed by Van Henten (1994). The state variables included air temperature, carbon dioxide concentration and absolute humidity. The input variables consisted of the solar radiation, wind speed, absolute humidity, air temperature and carbon dioxide concentration outside the greenhouse. The control variables were the temperature of the heating system, the aperture of the ventilation windows and the $\mathrm{CO}_{2}$ supply rate. The energy balance took into account the incoming solar radiation, the heating system, and the losses of energy through the greenhouse cover and by ventilation. The mass balance for $\mathrm{CO}_{2}$ included the supply of carbon dioxide, the assimilation of the crop canopy and the loss of $\mathrm{CO}_{2}$ by ventilation. The mass balance for humidity incorporated only the crop transpiration and the ventilation processes. It is worthwhile mentioning that this climatic model was coupled with a two state crop model in order to solve an open-loop optimal control problem (Van Henten et al., 1997; Van Henten and Bontsema, 2009). Although a formal local sensitivity analysis was carried out for the two states crop model, the climate model was not included in that study. The coupled model was calibrated and evaluated using data from Dutch glasshouses.

A five states dynamic model of greenhouse climate was used in the optimal control of the greenhouse (Tap, 2000; Tap et al., 1996a, b). The state variables included air, soil and heating pipe system temperatures, carbon dioxide and humidity concentration. The input variables were temperature, solar radiation, relative humidity, carbon dioxide concentration and wind velocity outside the greenhouse. The control variables consisted of the heat generated by the heating system, the windows aperture and the $\mathrm{CO}_{2}$ injection rates. The physical processes considered in the energy balance for air were the incoming solar radiation, the heat gain due to water condensation, the heat exchanges by the ventilation, across the greenhouse cover, with the heating pipe, with the soil and the loss of energy by the crop transpiration. In the case of the soil temperature, the heat fluxes considered were the exchange with the air and with the soil sub-layers. The energy balance of the heating pipe included the heat generated by the heating system, the incoming solar radiation in the pipes and the heat exchange between the heating pipe system and the greenhouse air. The mass balance for $\mathrm{CO}_{2}$ considered the injection of carbon dioxide, the $\mathrm{CO}_{2}$ exchange by ventilation, the crop respiration and the crop photosynthesis. The mass balance for humidity used the crop transpiration, the exchange of humidity due to ventilation and the loss of air humidity by water condensation. A local sensitivity analysis was performed for the coupled climatic and crop model. The model was calibrated by local search methods and its performance evaluated with data collected from Dutch glasshouses.

A three-state dynamic model of greenhouse climate was used to apply optimal control (Trigui, 2000). The states of the model were air temperature, absolute humidity and carbon dioxide (Trigui et al., 2001a). The control variables were heating, dehumidification and carbon dioxide injection. The energy balance for air (sensible heat balance) took into ac- 
count the heat transferred between the soil and the greenhouse air, the heat flux through the greenhouse cover, the heat flux from ventilation and infiltration, the heating system heat flux, the net incident radiation and the crop transpiration. The mass balance for humidity (latent heat balance) included crop transpiration, the mass of water vapor added or removed by humidification or dehumidification, the water vapor removed by infiltration and ventilation, and the water vapor condensation rate on the walls. The mass balance for $\mathrm{CO}_{2}$ considered the injection rate of $\mathrm{CO}_{2}$, the $\mathrm{CO}_{2}$ flux by ventilation and infiltration and the photosynthetic rate of $\mathrm{CO}_{2}$ consumption. Only a preliminary (neither local nor global) sensitivity analysis of the model was carried out. The performance of the model was evaluated (Trigui et al., 2001b) before its application to a dynamic optimization problem with data collected in Venlo-type glasshouses.

A three-state greenhouse climatic dynamic model has been developed and used in the optimal control by the evolutionary algorithms approach (Pohlheim and Heißner, 1996 1997, 1999). The state variables included air temperature, air vapor and $\mathrm{CO}_{2}$ concentration. The input control variables were the heating system, the ventilation system, $\mathrm{CO}_{2}$ enrichment and vapor injection. The input disturbances consisted of solar radiation, temperature, relative humidity, $\mathrm{CO}_{2}$ and wind speed. The physical processes in case of the energy balance of the air were the incoming solar radiation, the heat coming from the heating system, the heat exchange due to ventilation, the heat loss through the cover, the heat exchange due to crop transpiration, the heat exchange at floor, and the condensation or evaporation at the cover. The mass balance for air humidity considered the crop transpiration, water vapor injection, vapor exchange by ventilation and condensation or evaporation at cover. The mass balance for carbon dioxide took into consideration the $\mathrm{CO}_{2}$ enrichment, the $\mathrm{CO}_{2}$ assimilation by the crop and the exchange by ventilation. The greenhouse climatic model was extended with the dynamic of crop biomass in order to raise an optimal control problem (Ursem et al., 2002).

The model formulated by Van Ooteghem (2007) and described in Table 1 as Solar-1 model was used to raise and to solve an optimal control problem for the solar greenhouse model (Van Straten et al., 2011).

More recently a two-state greenhouse climate model has been formulated to the application of the optimal control approach with state constraints (Van Beveren et al., 2015a). The states of the model were air temperature and absolute humidity. The input variables included a total of fifteen outside climatic variables and control input signals. The physical processes in the energy balance considered the incoming solar radiation affected by the cover transmissivity, the closing and the transmissivity of the shadow and blackout screens; the convective heat loss through the greenhouse cover; the crop transpiration; the heating by artificial lighting; the heat loss by ventilation; the heating and cooling by the heat exchangers and the heating provided by the heating system. The physical processes included in the mass balance were the crop transpiration, the condensation to the cover, the condensation in the heat exchanger and the vapor flux by ventilation. The two states model was extended with a mass balance for carbon dioxide (Van Beveren et al., 2015b). The physical processes included in the $\mathrm{CO}_{2}$ balance were the carbon dioxide enrichment, the assimilation of $\mathrm{CO}_{2}$ by the crop and the $\mathrm{CO}_{2}$ exchange with outside air by ventilation. Both models were calibrated and evaluated with data collected from Dutch glasshouses.

\section{Greenhouse climate models for model predictive control}

A four-states discrete-time nonlinear model of the greenhouse climate was formulated and used in the model constrained predictive control approach (Piñon et al., 2005). The states were the temperature of the greenhouse cover, air, crop and floor. The disturbances in the model included direct and diffuse solar radiation and temperature outside the greenhouse and also the soil temperature at $10 \mathrm{~cm}$ depth. The only control variable was the heat coming from a heating or cooling system. This model was based on the more complex one proposed by Takakura (1993) and takes into account the main physical processes happening inside the greenhouse environment. The energy balance in the cover included the incoming solar radiation, the radiation exchange between the cover, and also the cover and the air inside the greenhouse. The heat exchanges included those due to convection; between the inside air and the cover, between the outside air and the cover, and also the latent heat by condensation. The energy balance of the air included the convective exchange with the cover, the crop, the soil and the air outside. The energy balance in the crop canopy included the radiation absorption by the crop canopy, the humidity exchange between crop and air, the heat exchange with air inside, outside the greenhouse and also with soil. The energy balance in the soil considered the incoming solar radiation on the soil, the heat exchange with the air and with the depth layers of the soil.

A three states dynamic model that uses air temperature, carbon dioxide and absolute humidity, based on the three states model from Van Henten (1994) and the greenhouse climate models from Tap (2000) was more recently used in model predictive control of temperature in a greenhouse (El Ghoumari et al., 2005).

A first-order autoregressive with external inputs model (ARX) was used to implement a model predictive controller in a greenhouse (Coelho et al., 2005). The output variable was the air temperature and inputs were the difference between inside and outside temperatures, the outside solar radiation, the difference between the heating pipe water and the air inside multiplied by the heating control input and the first mentioned input variable times the ventilation control input signal. The model was generated following the system identification procedure.

A three states dynamic model was proposed for optimization of water and energy in the greenhouse using Genetic Algorithms (Blasco et al., 2007). The state variables were air temperature, air absolute humidity and ground temperature (thermal mass). The disturbances input variables included solar radiation, wind speed, temperature and humidity outside the greenhouse. The controlled input variables considered window opening, fogging system and heating system. The physical processes included in the thermal balance for air were the incoming solar radiation, energy exchange through the cover by conduction and convection, energy loss by crop transpiration, energy exchange by ventilation, energy loss by nebulization, the heat provided by the heating system and the energy exchange between the air and thermal mass. The mass balance for humidity considered the exchange flux by ventilation, the crop transpiration and the humidity coming by the fogging system. The balance of the thermal mass took into consideration the incoming solar radiation, the energy exchange between the air and thermal mass and the energy loss through the ground. Although the model was calibrated none sensitivity or uncertainty analyses has been reported. A second-order Volterra series model was used to implement a nonlinear model predictive controller for greenhouse tem- 
perature (Gruber et al., 2011). The output variable was the air temperature and the input variables were the roof and lateral openings. The disturbances were the soil surface temperature and the air temperature, solar radiation, and wind speed outside the greenhouse.

\section{Greenhouse climate models for other control approaches (adaptive, robust, feedback, feedforward control)}

The greenhouse climate dynamic model proposed for the Watergy project (described above) was combined with an extended Kalman filter in order to estimate model parameters (Speetjens et al., 2009). The adaptive model of the greenhouse environment can be used for control purposes. A two states model of the greenhouse climate was used in the design of a Fuzzy Pseudo-Derivative Feedback Controller (Albright et al., 2001). The states were air temperature and the humidity ratio inside the greenhouse. This model included various disturbances such as outside temperature, solar radiation, and outside humidity ratio. The control inputs were the heat provided by a heater and the water capacity of the fog system. The energy balance in the air included the incoming solar radiation, the heat flux from the heating system, the heat loss by the fogging system, the heat exchange through the greenhouse cover and the heat loss by the natural ventilation. The mass balance for humidity included the humidity coming from the crop evapotranspiration, the humidity provided by the fogging system and the mass exchange by the natural ventilation. Later, this model was used in designing a feedback-feedforward approach to system linearization and decoupling for climate control of greenhouses (Pasgianos et al., 2003). Also, this model was used in designing an Extended and an Unscented Kalman nonlinear Kalman filters (Hameed and Sorensen, 2010) applied to design a Fuzzy Pseudo-Derivative Feedback Control system.

A two states dynamic model of greenhouse climate was used to design a robust controller (Bennis et al., 2008). The states included the temperature and humidity of the greenhouse air. The disturbances were global solar radiation, air temperature, humidity and wind speed outside the greenhouse. The control inputs considered the heating system, aperture of roof windows, shading screens and a fogging system. The energy balance included the incoming solar radiation, the heat provided by the heating system and the heat exchange by natural ventilation. The mass balance for humidity included the exchange by ventilation, the fogging and the heat given by the heating system. The model was calibrated and evaluated. A two states model has been used to design a robust control system for a greenhouse equipped with a high pressure fogging system (Linker et al., 2011). The states of the dynamic model were the enthalpy and the humidity ratio of the greenhouse air. The enthalpy balance took into consideration the incoming short wave solar radiation, the heat exchange with the outside by ventilation, the heat exchange through the greenhouse cover and the exchange of water vapor by ventilation. The humidity ratio balance of the model included the crop transpiration, the incoming humidity by the fogging system and the mass exchange by the natural ventilation.

A dynamic model for air humidity in the greenhouse was proposed by Stanghellini and De Jong (1995). The vapor content of the air inside the greenhouse was the only one state variable (De Jong and Stanghellini, 1996). The unsteady mass balance included the processes crop transpiration, condensation and ventilation. The input variables were global solar radiation, temperature of the heating pipes, leaf temperature, and wind speed outside the greenhouse, air movement inside the greenhouse, ambient dry and wet bulb temperatures. Control variables were crop transpiration rate and humidity. Recently this greenhouse humidity model has been applied to the environment of a semi-closed glasshouse located at Humboldt University Berlin, Germany (Salazar-Moreno et al., 2017).

A solar greenhouse system with an aquifer (thermal energy storage) for cooling and heating purposes was devised (Sethi and Sharma, 2007a). Aquifer water with a constant yearly temperature was used for both cooling (sensible and evaporative) during summer time and heating (sensible) on winter time. A dynamic model of the greenhouse climate with an aquifer was formulated (Sethi and Sharma, 2007b; Sethi et al., 2013). The state variables were the canopy temperature, greenhouse floor and air. Under several assumptions (Sethi and Sharma, 2007b), the dynamic model was reduced to only the air temperature inside the greenhouse. The model was used to evaluate both heating and cooling strategies of the greenhouse environment using the energy storage in the aquifer (Sethi and Sharma, 2007c).

TABLE 2. Dynamic models for optimal and predictive control.

\begin{tabular}{|c|c|c|c|c|c|c|c|c|}
\hline Model/author & States & Control inputs & Type & Calibration & Evaluation & UA & SA & Greenhouse type \\
\hline Van Henten & 5 & Heating, $\mathrm{CO}_{2}$ inj., window opening & Odes & Yes & Yes & No & Local SA & Glasshouses \\
\hline Tap & 5 & Heating, $\mathrm{CO}_{2}$ inj., window opening & Odes & Yes & Yes & No & Local SA & Glasshouses \\
\hline Trigui & 3 & Heating, window opening, humidification & Odes & Yes & Yes & No & Preliminary & Glasshouses \\
\hline Pohlheim & 4 & Heating, ventilation, $\mathrm{CO}_{2}$ inj., vapor_inj. & Odes & Yes & Yes & No & No & Glasshouses \\
\hline $\begin{array}{l}\text { Solar-1. } \\
\text { Van Ooteghem }\end{array}$ & 16 & $\begin{array}{l}\text { Valve positions for heating and cooling, } \\
\text { heat pump, heat exchanger, window } \\
\text { opening, ventilation with heat recovery }\end{array}$ & Odes & Yes & Yes & No & Local SA & Glasshouses \\
\hline Van Beveren & $2 / 3$ & $\begin{array}{l}\text { Heating, cooling, specific ventilation, } \\
\qquad \mathrm{CO}_{2} \text { inj., }\end{array}$ & Odes & Yes & Yes & No & No & Glasshouses \\
\hline Piñon & 4 & Heat flow & DE & No & No & No & No & NE \\
\hline El Ghoumari & 3 & Heating, window opening & Odes & Yes & Yes & No & No & Glasshouses \\
\hline Coelho & 1 & Heating, window opening & Arx & Yes & Yes & No & No & Polyethylene GH \\
\hline Blasco & 3 & Window opening, fogging, heating & Odes & Yes & Yes & No & No & Polyethylene GH \\
\hline
\end{tabular}

ODEs: ordinary differential equations, DE: difference equations, ARX: autoregressive with external inputs, NE: Not specified, UA: Uncertainty analysis, SA: Sensitivity analysis. 
TABLE 3. Greenhouse climate dynamic models for adaptive, robust, feedback/feedforward and other control approaches.

\begin{tabular}{|c|c|c|c|c|c|c|c|c|}
\hline Model/author & States & Control inputs & Type & Calibration & Evaluation & UA & SA & Greenhouse type \\
\hline Albright & 2 & Heating, fogging & ODEs & Yes & Yes & No & No & Glasshouses \\
\hline Bennis & 2 & $\begin{array}{l}\text { Heating, window opening, } \\
\text { shading, fogging }\end{array}$ & ODEs, DE & Yes & Yes & No & No & Glasshouses \\
\hline Linker & 2 & Ventilation, fogging & ODEs & Yes & Yes & No & No & Glasshouses \\
\hline Stanghellini & 1 & Crop transpiration, humidity & ODE & Yes & Yes & No & No & Glasshouses \\
\hline Sethi and Sharma & $1 / 3$ & Heating, cooling & ODEs & Yes & Yes & No & No & Polyethylene GH \\
\hline Rodriguez & 5 & $\begin{array}{l}\text { Window opening, heating, } \\
\text { shade screens }\end{array}$ & ODEs & Yes & Yes & No & No & Polyethylene GH \\
\hline
\end{tabular}

ODEs: ordinary differential equations, DE: difference equations, UA: Uncertainty Analysis, SA: Sensitivity Analysis.

A five states dynamic greenhouse climate model has been proposed recently. This model has been used to implement several control approaches (Rodríguez et al., 2015). The state variables included temperature of the cover, air, soil surface, and a first soil layer; air absolute humidity. The disturbances included the outside temperature, humidity, and wind speed, global and PAR solar radiation. The control variables were the positions of the natural ventilation and the shade screen; the heating system control signal. The physical processes included in case of the energy balance in the greenhouse cover were the solar radiation absorbed by the cover, the convective heat transfer with the greenhouse air, the convective heat transfer with the outside air, the condensation on the cover and the thermal radiation absorbed by the cover. The energy balance in the soil surface took into account the solar radiation absorbed by the soil surface, the convective flux with the greenhouse air, the thermal radiation absorbed by the soil surface, the conductive flux between the soil surface and the first soil layer located at $30 \mathrm{~cm}$ depth. The energy balance in the first soil layer included the conductive flux between the soil surface and the first soil layer; also the conductive flux between the first soil layer and the deep layer. The energy balance in the greenhouse air took into consideration the convective fluxes with the cover, the soil surface and the heating pipes; also the heat loss by the natural ventilation and infiltration, the crop transpiration and the evaporation. Finally, the mass balance in the greenhouse included the crop transpiration, the evaporation fluxes by the reservoirs and soil surface, the condensation at the cover and the outflow by the natural ventilation. The model was calibrated using measurements, however neither sensitivity nor uncertainty analyses have been reported.

Table 3 summarizes the most important characteristics of the greenhouse climate dynamic models for other control approaches.

\section{Discussion}

\section{On the physical processes included in modeling greenhouse climate}

From our review, it seems that dynamic models of greenhouse climate have mainly been founded on the first law of thermodynamics (energy/enthalpy) analysis and conservation of mass. The processes considered so far are long wave radiation, convection, absorption of short wave radiation by the ground, diffusion of heat in the ground, absorption of short radiation in photosynthesis, crop transpiration, water condensation and heat conduction through the greenhouse cover. A more physical (thermodynamic) modeling of greenhouse climate should include also exergy or both first and second laws of thermodynamics (Dincer and Cengel, 2001; Bronchart et al., 2013). Exergy analysis is needed especially in case of optimizing and designing greenhouse systems (Panwar et al., 2012; Kalogirou et al., 2016).

\section{On the uncertainty and sensitivity analysis of greenhouse climate dynamic models}

There is a lack of uncertainty analysis (UA) and sensitivity analysis (SA) in developing dynamic models of greenhouse climate (Tables 1-3, columns 7-8). None of the revised models were subjected to an uncertainty analysis even though a UA could help to increase the model reliability since it provides a quantitative measure of models outputs accuracy (Saltelli et al., 2008). Nowadays, two types of UA are available: frequentist (Wallach et al., 2014) and Bayesian such as the Generalized Likelihood Uncertainty Estimation (GLUE) method (Beven and Binley, 1992, 2014). Some models of greenhouse have been reported with only a preliminary sensitivity analysis; a few of them with a formal local sensitivity analysis and none with a global sensitivity analysis. Formulation of dynamic models of greenhouse climate should be complemented with both an uncertainty and sensitivity analysis because both analyses are necessary tools to assessing models. Currently, two general approaches for sensitivity analysis of systems are available: local methods which use and solve the sensitivity equations (Norton, 2015), and global methods which calculate sensitivity indexes based on Monte Carlo simulation and probability density functions specified for each analyzed input factor (Saltelli et al., 2000, 2004, 2008; Norton, 2015). Even more, the SA methods (local and global) are applicable to all types of dynamic models of greenhouse climate (Smith et al., 2008); models that use ordinary differential equations, difference equations, ARX or transfer functions. Models of greenhouse climate should consider any of these analyses in the same way that a global sensitivity analysis has been applied to models of greenhouse crops (López-Cruz et al., 2012a, b).

\section{On parameter estimation of greenhouse climate dynamic models}

Almost all the greenhouse climate models revised were calibrated; namely, some of the model parameters were estimated using measurements of some output variables of the model. The most commonly used method has been nonlinear least squares (NLS). Other optimization procedures, such as global optimization algorithms like stochastic and evolutionary algorithms, are rarely applied. The Bayesian approach, for parameter estimation, has not been used until now, but it can be very helpful in avoiding local minima convergence of classical methods (Wallach et al., 2014; Beven and Binley, 
2014). Furthermore, so far researchers have not applied more general methods that are available for estimation of parameters in models described by Ordinary Differential Equations (ODEs) such as orthogonal collocation or the generalized smoothing approach (Ramsay et al., 2007).

\section{On the data assimilation use in greenhouse climate dynamic models}

Data assimilation methods such as nonlinear Kalman filters have been used in a few greenhouse climate models. However, in general, several data assimilation methods such as the parameter estimation methods as mentioned above, state estimation methods such as nonlinear Kalman filters, particle filtering and variational filtering are all available (Liu and Gupta, 2007). These procedures could help to improve the quality of the models given that they allow the incorporation of measurements in model structure (Wallach et al., 2014).

\section{On evaluation of greenhouse climate dynamic models}

In almost all of the reported dynamic models of greenhouse climate, authors claim about the validation of their models. However, it is important to recall that mathematical models of Biosystems cannot be validated because it is not possible proving they are true (Oreskes, 1994). Therefore, it is more correct to say that a model has been extensively corroborated (Saltelli et al., 2008), which means that the model predictions have survived when comparing with several tests, for instance, several data and measurements sets. Nowadays is widely accepted the expression "model evaluation" instead of "model validation" (Wallach et al., 2014).

\section{Conclusions}

1) Several dynamic models of greenhouse climate have been developed mainly for two purposes: to increase the knowledge and to control and optimize the greenhouse system. The complexity of the theoretical models is larger than the one of applied models with respect to number of states, input variables and model parameters.

2) The development of mechanistic (thermodynamicsbased) greenhouse climate models is required in order to increase the knowledge and also to increase the possibilities of optimizing and designing better greenhouse systems.

3) Uncertainty analysis (frequentist and Bayesian) and sensitivity analysis (especially global sensitivity analysis) are required for all the formulated dynamic models of the greenhouse system in order to increase their reliability by these model assessing tools. The scope of applications of a greenhouse climate model could be extended if model development, calibration and evaluation are complemented with uncertainty and sensitivity analyses.

4) The application of new methods of parameter estimation such as global optimization algorithms, Bayesian methods, and general methods for parameter estimation in ordinary differential equations is needed.

\section{References}

Albright, L.D., Gates, R.S., Arvanitis, K.G., and Drysdale, A.E. (2001). Environmental control for plants on earth and space. IEEE Control Syst. Mag., October 2001, p. 28-47.

Baptista, F.J., Bailey, B.J., Navas, L.M., and Meneses, J.F. (2000). Validation of a dynamic greenhouse climatic model in Portugal. Acta Hortic. 534, 163-170. https://doi.org/10.17660/ ActaHortic.2000.534.18.

Baptista, F.J., Litago, J., Navas, L.M., and Meneses, J.F. (2001). Validation and comparison of a physical and statistical dynamic climatic model for a Mediterranean greenhouse in Portugal. Acta Hortic. 559, 479486. https://doi.org/10.17660/ActaHortic.2001.559.70.

Baptista, F.J, Bailey, B.J., Meneses, J.F., and Navas, L.M. (2010). Greenhouses climate modelling. Tests, adaptation and validation of a dynamic climate model. Span. J. Agric. Res. 8(2), 285-298. https:// doi.org/10.5424/sjar/2010082-1629.

Bennis, N., Duplaix, J., Enéa, G., Haloua, M., and Youlal, H. (2008). Greenhouse climate modelling and robust control. Comput. Electron. Agric. 61, 96-107. https://doi.org/10.1016/j.compag.2007.09.014.

Beven, K., and Binley, A. (1992). The future of distributed models: model calibration and uncertainty prediction. Hydrol. Process. 6, 279-298. https://doi.org/10.1002/hyp.3360060305.

Beven, K., and Binley, A. (2014). GLUE: 20 years on. Hydrol. Process. 28, 5897-5918. https://doi.org/10.1002/hyp.10082.

Blasco, X., Martínez, M., Herrero, J.M., Ramos, C., and Sanchis, J. (2007). Model-based predictive control of greenhouse climate for reducing energy and water consumption. Comput. Electron. Agric. 55, 49-70. https://doi.org/10.1016/j.compag.2006.12.001.

Boaventura Cunha, J. (2003). Greenhouse climate models. An overview. EFITA 2003 Conference, July 5-9, Debrecen, Hungary.

Bot, G.P.A. (1983). Greenhouse climate: from physical processes to a dynamic model. Ph.D. thesis (Wageningen, The Netherlands: Wageningen Agricultural University).

Bot, G.P.A. (1989a). Greenhouse simulation models. Acta Hortic. 245, 315-325. https://doi.org/10.17660/ActaHortic.1989.245.42.

Bot, G.P.A. (1989b). A validated physical model of greenhouse climate. Acta Hortic. 245, 389-396. https://doi.org/10.17660/ ActaHortic.1989.245.52.

Bot., G.P.A., Van de Braak, N., Challa, H., Hemming, S., Rieswijk, Th., Van Straten, G., and Verlodt, I. (2005). The solar greenhouse: state of the art in energy savings and sustainable energy supply. Acta Hortic. 691, 501-508. https://doi.org/10.17660/ActaHortic.2005.691.59.

Bronchart, F., De Paepe, M., Dewulf, J., Schrevens, E., and Demeyer, P. (2013). Thermodynamics of greenhouse systems for the northern latitudes: analysis, evaluation and prospects for primary energy saving. J. Environ. Mgt. 119, 121-133. https://doi.org/10.1016/j. jenvman.2013.01.013.

Coelho, J.P., de Moura Oliveira, P.B., and Boaventura Cunha, J. (2005). Greenhouse air temperature predictive control using the particle swarm optimisation algorithm. Comp. Electron. Agric. 49, 330-344. https://doi.org/10.1016/j.compag.2005.08.003.

De Jong, T., and Stanghellini, C. (1996). A model of greenhouse humidity suitable for control of crop processes. Acta Hortic. 406, 125-131. https://doi.org/10.17660/ActaHortic.1996.406.12.

De Zwart, H.F. (1996). Analyzing energy-saving options in greenhouse cultivation using a simulation model. Ph.D. thesis (Wageningen, The Netherlands: IMAG-DLO, Wageningen Agricultural University).

De Zwart, H.F. (1997). A simulation model to estimate prospectives of energy saving measures in horticulture. Acta Hortic. 443, 119127. https://doi.org/10.17660/ActaHortic.1997.443.15. 
Dincer, I., and Cengel, Y.A. (2001). Energy, entropy, and exergy concepts and their roles in thermal engineering. Entropy 3, 116149. https://doi.org/10.3390/e3030116.

Du, J., Bansal, P., and Huang, B. (2012). Simulation model of a greenhouse with a heat-pipe heating system. Appl. Energy 93, 268276. https://doi.org/10.1016/j.apenergy.2011.12.069.

Effat, M.B., Shafey, H.M., and Nassib, A.M. (2015). Solar greenhouses can be promising candidate for $\mathrm{CO}_{2}$ capture and utilization: mathematical modeling. Int. J. Energy Env. Eng. 6, 295-308. https:// doi.org/10.1007/s40095-015-0175-z.

El Ghoumari, M.Y., Tantau, H.J., and Serrano, J. (2005). Non-linear constrained MPC: real-time implementation of greenhouse air temperature control. Comp. Electron. Agric. 49, 345-356. https:// doi.org/10.1016/j.compag.2005.08.005.

Gruber, J.K., Guzmán, J.L., Rodríguez, F., Bordons, C., Berenguel, M., and Sánchez, J.A. (2011). Nonlinear MPC based on a Volterra series model for greenhouse temperature control using natural ventilation. Control Eng. Pract. 19, 354-366. https://doi.org/10.1016/j. conengprac.2010.12.004.

Haefner, J.W. (2005). Modeling Biological Systems. Principles and Applications (New York: Springer Science+Business Media Inc.).

Hameed, I.A., and Sorensen, C.G. (2010). A more energy efficient controller for the greenhouses climate control system. Appl. Eng. Agric. 26(3), 491-498. https://doi.org/10.13031/2013.29947.

Joudi, K.A., and Farhan, A.A. (2015). A dynamic model and experimental study for the internal air and soil temperatures in an innovative greenhouse. Energy Convers. Mgt. 91, 76-82. https://doi. org/10.1016/j.enconman.2014.11.052.

Kalogirou, S.A., Karellas, S., Braimakis, K., Stanciu, C., and Badescu, V. (2016). Exergy analysis of solar thermal collectors and processes. Prog. Energy Combust. Sci. 56, 106-137. https://doi.org/10.1016/j. pecs.2016.05.002

Linker, R., Kacira, M., and Arbel, A. (2011). Robust climate control of a greenhouse equipped with variable-speed fans and a variablepressure fogging system. Biosyst. Eng. 110, 153-167. https://doi. org/10.1016/j.biosystemseng.2011.07.010.

Liu, Y., and Gupta, H.V. (2007). Uncertainty in hydrologic modeling: toward an integrated data assimilation framework. Water Resour Res. 43(7), W07401. https://doi.org/10.1029/2006WR005756.

López-Cruz, I.L., Rojano-Aguilar, A., Salazar-Moreno, R., and RuizGarcía, A. (2012a). Global sensitivity analysis of greenhouse crop models. Acta Hortic. 952, 103-109. https://doi.org/10.17660/ ActaHortic.2012.952.11.

López-Cruz, I.L., Rojano-Aguilar, A., Salazar-Moreno, R., Ruiz-García A., and Goddard, J. (2012b). A comparison of local and global sensitivity analyses for greenhouse crop models. Acta Hortic. 957, 267-273. https://doi.org/10.17660/ActaHortic.2012.957.30.

López-Cruz, I.L., Fitz-Rodríguez, E., Torres-Monsivais, J.C., TrejoZúñiga, E.C., Ruíz-García, A., and Ramírez-Arias, A. (2014). Control strategies of greenhouse climate for vegetables production. In Biosystems Engineering: Biofactories and Food Production in the Century XXI, R. Guevara-González, and I. Torres-Pacheco, eds. (Switzerland: Springer International Publishing), p. 401-421.

Luo, W., De Zwart, H.F., Dai, J., Wang, X., Stanghellini, C., and Bu, C. (2005). Simulation of greenhouse management in the subtropics, Part 1: model validation and scenario study for the winter season. Biosyst. Eng. 90(3), 307-318. https://doi.org/10.1016/j. biosystemseng.2004.11.008.

Mashonjowa, E., Ronsse, F., Milford, J.R., and Pieters, J.G. (2013a) Modeling the thermal performance of a naturallyventilated greenhouse in Zimbabwe using a dynamic greenhouse climate model. Sol. Energy 91, 381-393. https://doi.org/10.1016/j.solener.2012.09.010.
Mashonjowa, E., Ronsse, F., Mubvuma, M., Milford, J.R., and Pieters, J.G. (2013b). Estimation of leaf wetness duration for greenhouse roses using a dynamic greenhouse climate model in Zimbabwe. Comp. Electron. Agric. 95, 70-81. https://doi.org/10.1016/j. compag.2013.04.007.

Mohammadi, B., Ranjbar, S.F., and Ajabshirchi, Y. (2018). Application of dynamic model to predict some inside environment variables in a semi-solar greenhouse. Inform. Proc. in Agric. (IPA) 5, 279-288. https://doi.org/10.1016/j.inpa.2018.01.001.

Navas, L.M., de la Plaza, S., García, J.L., Durán, J.M., and Retamal, N. (1998). Formulation and sensitivity analysis of a dynamic model of the greenhouse climate validation for a mild Mediterranean climate. Acta Hortic. 456, 305-312. https://doi.org/10.17660/ ActaHortic.1998.456.36.

Norton, J. (2015). An introduction to sensitivity assessment of simulation models. Environ. Modell. Softw. 69, 166-174. https://doi. org/10.1016/j.envsoft.2015.03.020.

Oreskes, N., Shrader-Frechette, K., and Belitz, K. (1994). Verification, validation, and confirmation of numerical models in the Earth Sciences. Science 263, 641-646. https://doi.org/10.1126/ science.263.5147.641.

Panwar, N.L., Kaushik, S.C., and Kothari, S. (2012). A review on energy and exergy analysis on solar drying systems. Renew. Sust. Energ. Rev. 16, 2812-2819. https://doi.org/10.1016/j.rser.2012.02.053.

Pasgianos, G.D., Arvanitis, K.G., Polycarpou, P., and Sigrimis, N. (2003). A nonlinear feedback technique for greenhouse environmental control. Comp. Electron. Agric. 40, 153-177. https:// doi.org/10.1016/S0168-1699(03)00018-8.

Pieters, J.G., Deltour, J.M., and Debruyckere, M.J. (1996a). Condensation and dynamic heat transfer in greenhouses. Part I: Theoretical model. Int. Agric. Eng. J. 5(3-4), 119-133.

Pieters, J.G., Deltour, J.M., and Debruyckere, M.J. (1996b). Condensation and dynamic heat transfer in greenhouses. Part II: Results for a standard greenhouse. Int. Agric. Eng. J. 5(3-4), 135-148.

Pieters, J.G., and Deltour, J.M. (1997). Performances of greenhouses with the presence of condensation on cladding materials. J. Agric. Eng. Res. 68, 125-137. https://doi.org/10.1006/jaer.1997.0187.

Piñon, S., Camacho, E.F., Kuchen, B., and Peña, M. (2005). Constrained predictive control of a greenhouse. Comp. Electron. Agric. 49, 317329. https://doi.org/10.1016/j.compag.2005.08.007.

Pohlheim, H., and Heißner, A. (1996). MENDEL'96 - $2^{\text {nd }}$ International Conference on Genetic Algorithms (Brno, Czech Republic), p. 112119.

Pohlheim, H., and Heißner, A. (1997). Optimal control of greenhouse climate using a short time climate model and evolutionary algorithms. ISHS/IFAC, $3^{\text {rd }}$ Workshop on "Mathematical and Control Applications in Agriculture and Horticulture”, p. 113-118.

Pohlheim, H., and Heißner, A. (1999). Optimal control of greenhouse climate using real-world weather data and evolutionary algorithms. In Proceedings of the Genetic and Evolutionary Computation Conference GECCO’99, W. Banzhaf, ed. (San Francisco, CA: Morgan Kaufmann), p. 1672-1677.

Rabbinge, R., and De Wit, C.T. (1989). Systems, models and simulation. In Simulation and Systems Management in Crop Protection, R. Rabbinge, S.A. Ward, and H.H. van Laar, eds. (Wageningen, The Netherlands: Pudoc), p. 3-16.

Ramsay, J.O., Hooker, J., Campbell, D., and Cao, J. (2007). Parameter estimation for differential equations: a generalized smoothing approach. J. Royal Statist. Soc., Series B, 69(5), 741-796. https://doi. org/10.1111/j.1467-9868.2007.00610.x. 
Reyes-Rosas, A., Molina-Aiz, F.D., Valera, D.L., López, A., and Khamkure, S. (2017). Development of a single energy balance model for prediction of temperatures inside a naturally ventilated greenhouse with polypropylene soil mulch. Comp. Electron. Agric. 142, 9-28. https://doi.org/10.1016/j.compag.2017.08.020.

Rodríguez, F., Berenguel, M., Guzmán, J.L., and Ramírez-Arias, A. (2015). Modeling and Control of Greenhouse Crop Growth (Cham, Switzerland: Springer International Publishing).

Salazar-Moreno, R., López-Cruz, I.L., Mauricio, A.M., Schmidt, U., and Miranda, L. (2017). A physical model for water balance in a semi-closed greenhouse. Acta Hortic. 1170, 183-191. https://doi. org/10.17660/ActaHortic.2017.1170.21.

Saltelli, A., Chan, K., and Scott, M., eds. (2000). Sensitivity Analysis. (New York: John Wiley \& Sons, Ltd.).

Saltelli, A., Tarantola, S., Campolongo, F., and Ratto, M. (2004). Sensitivity Analysis in Practice. A Guide to Assessing Scientific Models. (Chichester: John Wiley \& Sons, Ltd.).

Saltelli, A., Ratto, M., Adres, T., Campolongo, F., Cariboni, J., Gatelli, D., Saisana, M., and Tarantola, S. (2008). Global Sensitivity Analysis. The Primer (Chichester: John Wiley \& Sons, Ltd.).

Sethi, V.P., and Sharma, S.K. (2007a). Greenhouse heating and cooling using aquifer water. Energy 32, 1414-1421. https://doi. org/10.1016/j.energy.2006.10.022

Sethi, V.P., and Sharma, S.K. (2007b). Thermal modelling of a greenhouse integrated to an aquifer coupled cavity flow heat exchanger system. Sol. Energy 81, 723-741. https://doi org/10.1016/j.solener.2006.10.002.

Sethi, V.P., and Sharma, S.K. (2007c). Experimental and economic study of a greenhouse thermal control system using aquifer water. Energy Convers. Mgt. 48, 306-319. https://doi.org/10.1016/j. enconman.2006.04.003.

Sethi, V.P., Sumathy, K., Lee, C., and Pal, D.S. (2013). Therma modeling aspects of solar greenhouse microclimate control: A review on heating technologies. Sol. Energy 96, 56-82. https://doi. org/10.1016/j.solener.2013.06.034.

Setiawan, A., Albright, L.D., and Phelan, R.M. (2000). Application of pseudo-derivative-feedback algorithm in greenhouse air temperature control. Comp. Electron. Agric. 26, 283-302. https:// doi.org/10.1016/S0168-1699(00)00081-8.

Smith, E.D., Szidarovszky, F., Karnavas, W.J., and Bahill, A.T. (2008) Sensitivity analysis, a powerful system validation technique. The Open Cybernetics and Systemics J. (TOCSJ) 2, 39-56. https://doi.org /10.2174/1874110X00802010039.

Speetjens, S.L. (2008). Towards model based adaptive control for the Watergy greenhouse. Design and implementation. Ph.D. thesis (Wageningen. The Netherlands: Wageningen University), 198 pp.

Speetjens, S.L., Xu, J., Van Straten, G., and Stigter, H. (2006). A model for the climate of an innovative closed greenhouse for model based control. Acta Hortic. 718, 323-330. https://doi.org/10.17660/ ActaHortic.2006.718.37.

Speetjens, S.L., Stigter, J.D., and Van Straten, G. (2009). Towards an adaptive model for greenhouse control. Comp. Electron. Agric. 67, 1-8. https://doi.org/10.1016/j.compag.2009.01.012.

Speetjens, S.L., Stigter, J.D., and Van Straten, G. (2010). Physics-based model for a water-saving greenhouse. Biosyst. Eng. 105, 149-159. https://doi.org/10.1016/j.biosystemseng.2009.06.026.

Stanghellini, C., and De Jong, T. (1995). A model of humidity and its applications in a greenhouse. Agric. For. Meteorol. 76, 129-148. https://doi.org/10.1016/0168-1923(95)02220-R.
Takakura, T. (1993). Climate under Cover. Digital Dynamic Simulation in Plan Bio-Engineering (Dordrecht: Kluwer Academic Publishers). https://doi.org/10.1007/978-94-011-1658-9.

Takakura, T., and Fang, W. (2002). Climate under Cover, $2^{\text {nd }}$ edn. (Dordrecht: Kluwer Academic Publishers). https://doi. org/10.1007/978-94-010-0583-8.

Takakura, T., Jordan, K.A., and Boyd, L.L. (1971). Dynamic simulation of plant growth and environment in the greenhouse. Trans. ASABE 14(5), 964-971. https://doi.org/10.13031/2013.38432.

Taki, M., Ajabshirchi, Y., Ranjbar, S.F., Rohani, A., and Matloobi, M. (2016). Modeling and experimental validation of heat transfer and energy consumption in an innovative greenhouse structure. Inform. Proc. in Agric. (IPA) 3, 157-174. https://doi.org/10.1016/j. inpa.2016.06.002.

Taki, M., Rohani, A., and Rahmati-Joneidabad, M. (2018). Solar thermal simulation and applications in greenhouse. Inform. Proc. in Agric. (IPA) 5, 83-113. https://doi.org/10.1016/j.inpa.2017.10.003.

Tap, R.F. (2000). Economics-based optimal control of greenhouse tomato crop production. Ph.D. thesis (Wageningen. The Netherlands: Wageningen University).

Tap, R.F., Van Willigenburg, G., and Van Straten, G. (1996a). Receding horizon optimal control of greenhouse climate based on the lazy man weather prediction. IFAC, $13^{\text {th }}$ Triennial World Congress (San Francisco), p. 387-392.

Tap, R.F., Van Willigenburg, L.G., and Van Straten, G. (1996b). Experimental results of receding horizon optimal control of greenhouse climate. Acta Hortic. 406, 229-238. https://doi. org/10.17660/ActaHortic.1996.406.23.

Tavares, C., Gonçalves, A., Catro, P., Loureiro, D., and Joyce, A. (2001). Modelling an agriculture production greenhouse. Renew. Energ. 22, 15-20. https://doi.org/10.1016/S0960-1481(00)00030-6.

Trigui, M. (2000). Strategy for the optimal climate control of greenhouse tomatoes. Ph.D. thesis (Montreal, Canada: McGill University).

Trigui, M., Barrington, S., and Gauthier, L. (2001a). A strategy for greenhouse climate control, Part I: Model development. J. Agri. Eng. Res. 78(4), 407-413. https://doi.org/10.1006/jaer.2000.0647.

Trigui, M. Barrington, S., and Gauthier, L. (2001b). A strategy for greenhouse climate control, Part II: Model validation. J. Agri. Eng. Res. 79(1), 99-105. https://doi.org/10.1006/jaer.2000.0648.

Udink ten Cate, A.J. (1983). Modeling and (adaptive) control of greenhouse climates. Ph.D. thesis (Wageningen, The Netherlands: Wageningen Agricultural University).

Udink ten Cate, A.J. (1985). Modelling and simulation in greenhouse climate control. Acta Hortic. 174, 461-467. https://doi. org/10.17660/ActaHortic.1985.174.61.

Udink ten Cate, A.J., and Van de Vooren, J. (1984). New models for greenhouse climate control. Acta Hortic. 148, 277-285. https://doi. org/10.17660/ActaHortic.1984.148.34.

Ursem, R.K., Krink, T., and Filipič, B. (2002). A numerical simulator of a crop-producing greenhouse. EVALife Techn. Report no. 2002-01. (Aarhus, Denmark: University of Aarhus).

Vadiee, A., and Martin, V. (2012). Energy management in horticultural applications through the closed greenhouse concept, state of the art. Renew. Sust. Energ. Rev. 16, 5087-5100. https://doi.org/10.1016/j. rser.2012.04.022. 
Vadiee, A., and Martin, V. (2013a). Energy analysis and thermoeconomic assessment of the closed greenhouse: The largest commercial solar building. Appl. Energy 102, 1256-1266. https:// doi.org/10.1016/j.apenergy.2012.06.051.

Vadiee, A., and Martin, V. (2013b). Thermal energy storage strategies for effective closed greenhouse design. Appl. Energy 109, 337-343. https://doi.org/10.1016/j.apenergy.2012.12.065.

Vadiee, A., and Martin, V. (2014). Energy management strategies for commercial greenhouses. Appl. Energy 114, 880-888. https://doi. org/10.1016/j.apenergy.2013.08.089.

Van Beveren, P.J.M., Bontsema, J., Van Straten, G., and Van Henten, E.J. (2015a). Minimal heating and cooling in a modern rose greenhouse. Appl. Energy 137, 97-109. https://doi.org/10.1016/j. apenergy.2014.09.083.

Van Beveren, P.J.M., Bontsema, J., Van Straten, G., and Van Henten, E.J. (2015b). Optimal control of greenhouse climate using minimal energy and grower defined bounds. Appl. Energy 159, 509-519. https://doi.org/10.1016/j.apenergy.2015.09.012.

Van Henten, E.J. (1994). Greenhouse climate management: an optimal control approach. Ph.D. thesis (Wageningen, The Netherlands: Wageningen University).

Van Henten, E.J., and Bontsema, J. (2009). Time-scale decomposition of an optimal control problem in greenhouse climate management. Control Eng. Pract. 17, 88-96. https://doi.org/10.1016/j. conengprac.2008.05.008.

Van Henten, E.J., Bontsema, J., and Van Straten, G. (1997). Improving the efficiency of greenhouse climate control: an optimal control approach. Neth. J. Agric. Sci. 45, 109-125.

Van Ooteghem, R.J.C. (2007). Optimal control design for a solar greenhouse. Ph.D. thesis (Wageningen, The Netherlands: Wageningen University).

Van Ooteghem, R.J.C., Van Willigenburg, L.G., and Van Straten, G. (2005). Receding horizon optimal control of a solar greenhouse. Acta Hortic. 691, 797-805. https://doi.org/10.17660/ ActaHortic.2005.691.98.

Van Straten, G. (2008). What can systems and control theory do for agricultural science? Automatika 49(3-4), 105-117.

Van Straten, G., Van Willigenburg, G., Van Henten, E., and Van Ooteghem, R. (2011). Optimal Control of Greenhouse Cultivation (Boca Raton: CRC Press).

Wallach, D., Makowski, D., Jones, J.W., and Brun, F. (2014). Working with Dynamic Crop Models. Methods, Tools, and Examples for Agriculture and Environment. (Amsterdam: Elsevier Academic Press).

Wei, B., Guo, S., Wang, J., Li, J., Wang, J., Zhang, J., Qian, C., and Sun, J. (2016). Thermal performance of single span greenhouses with removable back walls. Biosyst. Eng. 141, 48-57. https://doi. org/10.1016/j.biosystemseng.2015.11.008.

Yang, Q. (2012). Energy efficient heating technologies and models in lean-to Chinese solar greenhouses: A review. Acta Hortic. 957, 83-89. https://doi.org/10.17660/ActaHortic.2012.957.8.

Zaragoza, G., Buchholz, M., Jochum, P., and Pérez-Parra, J. (2007) Watergy Project: towards a rational use of water in greenhouse agriculture and sustainable architecture. Desalination 211(1-3), 296-303. https://doi.org/10.1016/j.desal.2006.03.599.
Received: Jan. 26, 2018

Accepted: Sep. 19, 2018

Addresses of authors:

I.L. López-Cruz ${ }^{1, *}$, E. Fitz-Rodríguez ${ }^{1}$, R. Salazar-Moreno ${ }^{1}$,

A. Rojano-Aguilar ${ }^{1}$ and M. Kacira ${ }^{2}$

${ }^{1}$ Graduate Agricultural Engineering Program, University of Chapingo, Chapingo, Mexico

${ }^{2}$ Agricultural and Biosystems Engineering Dept., University of Arizona, Tucson, USA

* Corresponding author;

E-mail: ilopez@correo.chapingo.mx 